\title{
The concept of complimenting in light of the Moore language in Burkina Faso
}

\author{
Mahamadou Sawadogo \\ Ouaga I Pr Joseph Ki-Zerbo University, Burkina Faso
}

This paper sheds light on the concept of complimenting, based on its practice in the Moore language spoken in Burkina Faso, West Africa. It revisits Holmes' (1986) definition of "compliments" and proposes a model which gives new insight into the concept of complimenting behaviour across languages and cultures. The proposed model may have implications for our understanding of politeness strategies as proposed by Brown and Levinson (1987), particularly with the urge to integrate third person in the model, as a close examination of data from Moore would suggest. The data analyzed were collected in naturally occurring discourse.

Keywords: compliment, complimenting, complimenter, complimentee, Moore, implicit, politeness strategy, third person/party

\section{Introduction}

Since Pomerantz's (1978) pioneering discussion, interest in compliments and compliment responses has kept surging as rightly predicted by Holmes in her illuminating paper: "Research in complimenting behavior will clearly prove a fruitful and fascinating area of pragmatic and sociolinguistic study for considerable time to come" (Holmes $(1986,505))$. As a matter of fact, there are many very recent studies on compliments (Shokouhi \& Rezaei 2015) adding to the flourishing literature in the field.

Believed to be a major culture-revealing linguistic behaviour, complimenting and its twin speech act, responding to compliments, have been thoroughly investigated following various and sometimes divergent methodologies according to the objectives in view. The sample sizes vary from as low as one informant (!) (Duan (2011)) to more than 600, as most of the patterns of compliments, which are basically formulaic language types, are said to be reliably apparent in smaller 
as in larger samples (Holmes (1986: 505)). Interest is growing in cross-cultural pragmatic study of complimenting with a pedagogical orientation. For a review of the related literature the reader is referred to Furko \& Dudas (2012), Grossi (2009), Tajeddin \&Yasdanmehr (2012), and Valkova (2013). However, researchers appear not to be totally in tune with regard to the definition and the concept of complimenting. What actually counts as complimenting? Does complimenting behaviour have universal characteristics?

My objective in this paper is to shed more light on the concept of complimenting itself on the basis of observation of its realization patterns in the Moore language. For now, I do not address the specific formulae used in compliments and compliment responses in Moore, nor do I attempt to categorize them in terms of topics (appearance, ability, performance ...) or linguistic forms (lexical or syntactic), regardless of their frequency of occurrence according to the situational context. I simply seek to examine the concept of complimenting in light of specific examples of compliments and compliment responses in Moore as observed in naturally occurring exchanges.

Various studies have contributed to making it common knowledge that complimenting behaviour is universal, though it varies across cultures taking on forms that may at times conceal its nature from a layperson or a foreigner. However, I fully agree with Holmes (1986) that "more cross-cultural data is needed so that universal characteristics of complimenting behaviour can be distinguished from the preferred cultural patterns of a particular group" (Holmes $(1986,505))$. This paper is a contribution towards that goal.

\section{Methodology}

Data on Moore compliments were collected in naturally occurring discourse. In an attempt to exclude or minimize influence from other (local or foreign) languages or cultures, I shunned large, cosmopolitan cities like Ouagadougou, the capital city of Burkina Faso and of the Mossi people as well, and went to a small and remote Mossi village, Niangouela (in the northern part of Burkina Faso), to hunt for what I assumed to be genuine Moore complimenting. As a matter of fact, some studies suggest the high possibility of such influence from other cultures in similar situations, which is referred to as "pragmatic transfer" or "sociolinguistic transfer" (see Othman (2011) and Franch (1998)). The data were collected in recording or by note taking completed by interviews of resource people, and by my own introspection (since I am a native speaker of Moore). To identify my compliment data, I relied on the usual compliment IFIDs (Illocutionary force indicators, (Searle (1969)), and native-speaker intuition for the interpretation of some exchanges as implicit compliments. This method could amount to a combination of what Clark and Bangerter 
$(2004,25)$ would refer to as "armchair" and "field" methods, that is, linguistic or pragmatic research methods based on intuited - though not imagined - data and natural data (cited by Jucker 2009, 1615).

\section{What is complimenting?}

Such a question may seem utterly untimely after so many illuminating studies (Holmes (1986, 1988, 1995), Wolfson (1981, 1983), Herbert $(1986,1989,1990)$, Manes \& Wolfson (1981), etc.) on the topic have already provided great insight into the concept and function of compliments and the responses to them. There is no point in reinventing the wheel. Consistent and coherent categories of compliments and compliment responses have also been proposed across diverse languages and cultures, with discussion of their rates of occurrence (Holmes 1986, 1988, 1995) Herbert (1990), Daikuhara (1986), Chen (1993), Jucker et al. (2008), etc.), their place within discourse (Bruti (2006), Valkova (2013) Lewandowska-Tomaszcyk (1989) etc.), and some pedagogical implications (Holmes \& Brown (1987), Shokouhi \& Rezaei (2015)). However, looking at my complimenting data in Moore, my native language, I faced difficulties fitting some of what I consider to be complimenting behaviour within the types suggested in the literature. I had either to reject them as complimenting behaviour or attempt to revisit the concept itself in order to allow room for them. I opted for the second alternative, providing data to support my hypothetical types.

Mustapha (2012a) observes that researchers into complimenting are split over the necessity or not to provide a working definition for their subject since, on the one hand, "compliments make themselves readily identifiable [by native speakers] in discourse" but, on the other hand, are also complex in nature and multi-functional as a speech act, and furthermore display a lot of similarity with speech acts of the same pool such as praising, congratulating, and flattering (for a distinction between them, see also Lewandowska-Tomaszcyk (1989)). I contend with Mustapha (2012a) that a definition of complimenting is needed, though I would advocate for culture-specific descriptions rather than culture-specific definitions, that is, descriptions of its varied realisation patterns across cultures rather than attempts to work out definitions that vary from culture to culture. Based on his field work experience and analysis of 1200 compliment data from speakers of Nigerian English in Lagos, Mustapha (2012b) has also resorted to the modification of some of the definitions in the literature to fit part of his data and to distinguish them from, say, praises and congratulations. Though modification may be necessary for the definition of complimenting, I contend that we should rather begin by taking the classical definition more strictly.

Holmes' $(1986,1988)$ carefully worded definition is one of the most widely quoted in earlier and more recent studies on "compliment and or compliment 
responses". It stipulates that "a compliment is a speech act which explicitly or implicitly attributes credit to someone other than the speaker, usually the person addressed, for some "good" (possession, characteristic, skill, etc.) which is positively valued by the speaker and the hearer" Holmes (1986, 485; 1988, 446).

Though Jucker (2009) relevantly points out that "Several elements of this definition deserve some discussion" (Ibid: 1612), little or no discussion of it has actually been made by scholars. Jucker (Ibid) on his part signals that "there has to be a link from the "someone" who is attributed credit to the addressee of the compliment, otherwise the utterance is more likely to be understood as praise on some third party but not as compliment".

As shown in Diagram (1), eight potential types of compliments (C1-8) derive from Holmes' (1986) definition.

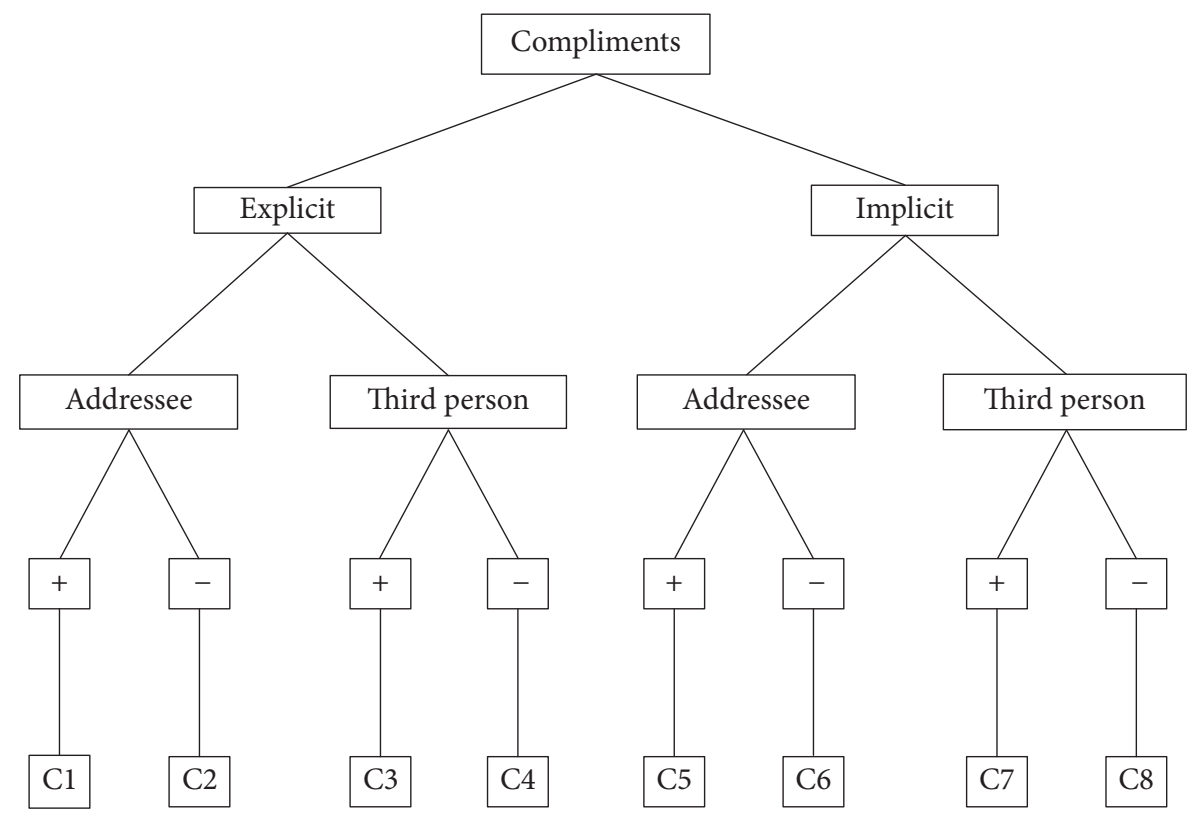

Diagram 1. Compliment types derived from Holmes' (1986) definition.

Diagram reading:

- Top line: "Compliments" = credit attributed by speaker (positive value)

- Second line: Explicitness/implicitness of compliment

- Third line: Complimentee (Addressee or third person)

- Fourth line: Complimentee's assessment of credit attributed to him/her (positive or negative)

- Bottom line: Resulting potential types of compliments (C1, C2 ... C8) 
If we consider Holmes' "which is positively valued by the speaker and the hearer" criterion, then types $\mathrm{C} 2, \mathrm{C} 4, \mathrm{C} 6$, and C8, are logically ruled out as compliments because of the discrepancy in complimenter and complimentee's assessment of the "credit" involved. The complimenter's assessment is logically positive (the sincerity conditions being met) whereas the complimentee's happen to be negative. However, most studies, if not all, would consider - and rightly so - types C2 and C6 as compliments, but ones that logically call for rejection by the potential complimentee since the latter appears not to share the "good" credit value of the compliments. As it appears, sharing the complimenter's good credit does not secure a compliment from rejection as there may be other social or cultural reasons for not accepting a compliment (see Holmes 1988, 452). Therefore, when its sincerity conditions are met, the speech act of complimenting is considered duly realized by the speaker independently of the complimentee's assessment of the credit accorded him. Of course, the complimentee's assessment is not known by the complimenter at the moment but the latter is assumed to be pleased with the credit - which is supposed to be the primary function of complimenting.

Holmes (1986) goes on to say that "compliments normally attribute the valued "good" to the addressee, and even when a compliment apparently refers to a third person, it may well be indirectly complimenting the addressee" Holmes (1986, 486; 1988, 447). She, therefore, logically rules out - for the purpose of her study - utterances attributing credit to a third person as compliments, preferring to count them as simple "positive evaluation". This is tantamount to ruling out types $\mathrm{C} 3, \mathrm{C} 4, \mathrm{C} 7$, and C8 in Diagram 1. However, data seem to suggest that in the Mossi culture, not only can a third person, present or absent from the "setting and scene" (Hymes 1974, 55), be complimented, but also this could be considered the most indirect form of complimenting (see Examples (1) and (2).

(1) Context: A husband, about a meal he has just had.

Moore English equivalent

Husband:“Wayy! A Hawa zẽedã Literally: INTERJECTION - Hawa - sauce nooma!” taste good!"

Meaning: Wow! Hawa's sauce is really good!

The husband said this in the absence of his wife, Hawa, which confers on it the status of a "simple positive evaluation" in Holmes' (1986) view. However, it was said in the presence of Hawa's child who was sure to report it to her as the intended complimentee. Hawa is expected to acknowledge and respond to this compliment one way or another. The cultural background here is that males and females in traditional Mossi society have their meals in separate places distant enough to obliterate the distinct hearing of conversation from either group. 
This complimenting behaviour is not rare and is authenticated by the fact that when the complimenter is unsure whether the compliment will be reported $\mathrm{s} / \mathrm{he}$ may be more explicit to the third party as in (2):

(2) A guest just after a meal, talking to a child:

\section{Moore}

Visitor: "Wayy! Yeel f ma t’a zẽedã nooma!

\section{English Equivalent}

Literally: INTERJECTION, Tell-your- motherthat- her- sauce - taste good!

Meaning: Wow! Tell your mother that her sauce is really good!

What may be striking for the foreigner is that the complimentee may not get their compliment - at least not directly- even if they were present in the setting and scene. In both (1) and (2), the addressee (the child) would understand that the compliment is primarily intended for the third party. Still, even in the presence of third party complimentee, the complimenter can 'speak' to the complimentee via the addressee as in Example (3):

(3) Context: A visitor talking to a child in the mother's presence after a delicious meal cooked by the child's mother.

Moore

Visitor: "Wayy! F ma zẽedã nooma!”
English equivalent

Literally: INTERJECTION. Your-mothersauce - tastes - good.

Meaning: Wow! Your mother's sauce is really good!

The child's mother, though not directly addressed, is within hearing and is meant to interpret this compliment as intended for her, and she may respond. This type of indirectness is preferred by Mossi gentlemen when addressing appearance compliments to unknown girls in the street. It is different from the type signalled by Yuan (2002: 286) where the complimenter uses the strategy of quoting a third party as saying something complimentary about the addressee, as in the following example:

Context: The Researcher $(\mathrm{R})$ is speaking to the wife of a former classmate.

$\mathrm{R}$ : "Sun Ping said that the preserved vegetables you made were the most delicious!"

It seems reasonable to posit that the above examples in Moore question the solely addressee-oriented view of complimenting as suggested by Holmes (1986), Furko \& Dudas (2012), Hobbs (2003) quoted by Furko \& Dudas (2012) among others.

Let us examine a further Example (4) from our data in Moore. 
(4) Context: The complimentee, a teenager, is being complimented by an unknown man for brilliantly passing his exams.

\begin{tabular}{|c|c|}
\hline Moore & English equivalent \\
\hline Man: "Wayy! F ma rog biiga!" & $\begin{array}{l}\text { Literally: INTERJECTION - Your- mother- } \\
\text { bear- child! } \\
\text { Meaning: "What a fantastic child you are!" }\end{array}$ \\
\hline Teenager: [smiles]... & Teenager: [smiles]... \\
\hline
\end{tabular}

Here, the act of complimenting is meant for the teenager. As women normally bear children, the conversational implicature of the tautology involved here is "What an exceptionally good/exemplary child you are?". Though the child's mother is explicitly complimented, it is actually the teenager who is complimented, and he is not likely to extend the compliment to his mother as is the case in Examples ( 1 \& 3 ).

Holmes $(1988,447 ; 1995,117)$ reports a similar case but in her example the child's mother was present and considered herself as the actual complimentee:

(4bis) Complimenter: What a polite child!

Recipient [the child's mother]: Thank you. We do our best.

However, the addressee is not specified and we don't know if the child had a chance to respond were s/he the addressee, and assuming s/he was of age to respond. This supports Holmes' (1986, 485-486) view that "when a compliment apparently refers to a third person, it may well be indirectly complimenting the addressee"

An issue that can be raised about third party as complimentee is the unavailability of their assessment of the credit accorded to them, thus making the addressee the sole counter-assessor. The addressee's response will depend on the following:

- Their own assessment of the credit accorded by the complimenter, which may be positive or negative,

- Their social relationship with the complimentee and the complimenter (social distance),

- The participants and particularly the presence or absence of the actual third party complimentee in the setting or scene as described in Hymes' SPEAKING framework (Hymes 1974, 53-62)).

In light of those examples, complimenting - in Moore at least - seems to function as illustrated in Diagram (2).

As rightly suggested in Hymes' (1974) ethnographic framework (SPEAKING), all the factors that are relevant in understanding a particular communicative event must be considered in its interpretation. In this respect, this diagram indicates that the complimenting act in Moore can be directed straight to the addressee or to the 


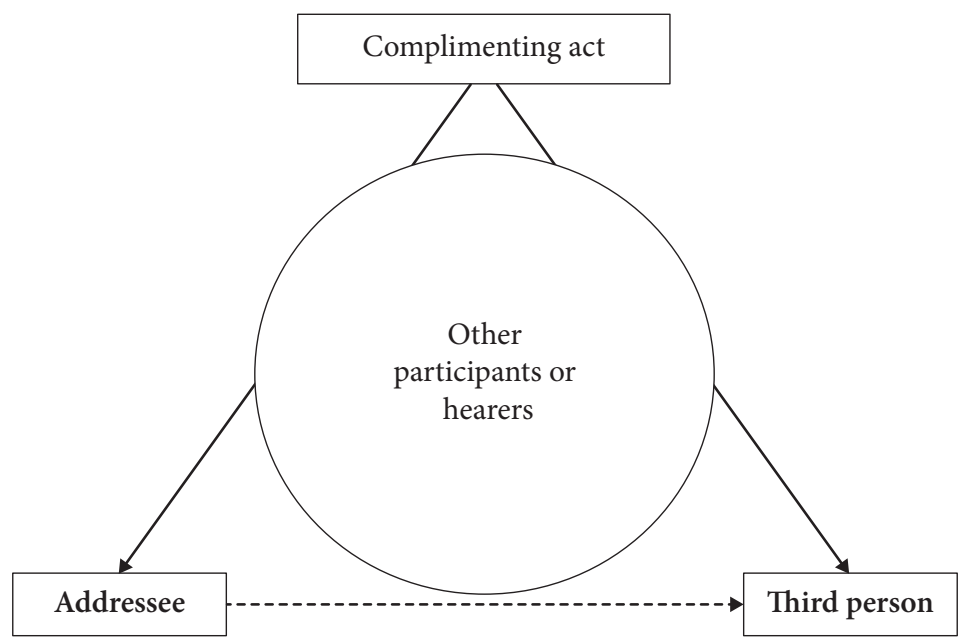

Diagram 2. Complimenting addressee or third person

third person (who may not be directly addressed even when present, or it can be later transferred indirectly to the third person (when absent) by the addressee or other participants or hearers. The presence of other participants may influence, incite, dissuade, or even impose the complimenting act (sincere or not). As for the response of an absent third-person complimentee, it is probable that, when needed, it will follow the reverse route of third party complimenting, i.e., from the complimentee to the complimenter via another person (addressee, other participants, or else).

If the above examples from Moore are credited as authentic complimenting behaviour, then C3, C4, C7, and C8 in Diagram 1 are potential compliment types to be added to Holmes' (1986) definition.

By excluding a third person, Holmes' (1986) definition retains only two out of eight of the potential complimenting types in Diagram 1 (namely, C1 and C5, where both the complimenter and the complimentee agree on the credit "good" value) that is, $25 \%$ at most. Such a restriction could reduce chances to capture what is felt as complimenting behaviour across languages and cultures all over the world, thus giving room to ethnocentric bias. Wierzbicka (1991) may therefore be right in cautioning "against attempts to formulate language universals at the expense of culture-specifics" (Wierzbicka (1991, 67-68) cited in Pohl (2004: 3)). Not only should the criterion of "positively valued [...] by the hearer" be removed from the definition of complimenting but also it should be seen as possibly multidirectional (see Examples (3), (4), and Diagram (2)). 


\section{Some terminological issues}

Discrepancy in according utterances the pragmatic force of complimenting and determining complimentee status may also be traced to differences in the acceptance of some key terms in discourse analysis. Many of the definitions I have come across in the literature on complimenting do not seem to comply with the strict meanings of some recurrent and core terms generally found in discourse analysis, which results in confusion. Such terms include "addresser", "addressee", "speaker", "hearer", "complimenter", "complimentee", and even "compliment". A good attempt to unravel this confusion could be made by paraphrasing and adapting Cook's (1989, 25$)$ definition of addresser and addressee, as follows:

- The complimenter ["addresser" in Cook (1989: 25)] is the person who originates the act of complimenting ["message" in Cook (1989: 25)], usually the speaker or sender but not necessarily - as e.g. when there is a spokesperson or an interpreter.

- The complimentee ["addressee" in Cook (1989: 25)] is the person to whom the act of complimenting ["message" in Cook (1989: 25)] is directed, usually the hearer or receiver but not necessarily - as e.g. when there is a spokesperson or an interpreter.

It follows from the above definitions that the complimenter or addresser is not necessarily the speaker, and that the complimentee or addressee is not necessarily the hearer or interlocutor. Just as, in discourse, the person spoken to is not necessarily the addressee, in complimenting, the person spoken to is not necessarily the complimentee. In Examples (1), (2), (3) and (4) the woman is the complimentee but she was never the person spoken to. At best, she was a hearer as a result of being within hearing. Therefore, it would not be fair to reduce the husband's nor the visitor's utterances to "simple positive evaluation", since there is obviously - as the native speaker feels, of course! - an intention for this positive evaluation to travel (by air or whatever other conduit) to the ear of the woman. This is the actual illocutionary force of their utterances, which is complimenting per se. Holmes (1988) actually concurs with this view as she rightly contends that "the definition of the term 'compliment' would [...] include utterances attributing credit to someone other than the addressee [...], it is the attributed underlying intention that [is] the guiding criterion, rather than any surface form indicators" (Holmes $(1988,447)$ ).

Furthermore, "complimenting", the speech act, and "compliment", its product, are often used interchangeably, adding to the confusion. The actual realization of complimenting in any specific context is a compliment, which can be described in 
terms of either linguistic items (words and syntactic structures) or non-linguistic items (gestures like 'thumbs up' among others). Complimenting is, on the other hand, described in terms of realization patterns (see Valkova (2013)).

\section{Implicit compliments in Moore}

Holmes' (1986) definition clearly indicates that complimenting can be performed explicitly or implicitly and this is attested in the abundant literature on complimenting. Explicit compliments are understood as those whose form overtly suggests complimenting as in "Your dress is wonderful!" (For details on the lexical and syntactic forms of complimenting see Holmes (1986) and Wolfson (1981) among others.) On the other hand, implicit compliments are understood as those whose nature is concealed in the lexical and syntactic forms used in the complimenting act as in this example provided by Agyekum (2010), "As for today you should have been somewhere else better than here" which implies that the complimentee is so dressed up that s/he deserves being among VIPs or in a public place to be admired.

In light of further examples from the Moore language, complimenting may take on a rather extreme form of implicitness as in Examples (5) and (6) in Moore, below:

(5) Context: A Mossi man who actually compliments a Gulmancema man (a "joking relative" from another ethnic group) for his new garment.

Moore

Complimenter: "Yaa bõe me maam fu yonglg la woto?

Complimentee: Fo tõe n paam yãoã? Complimenter: Karisa!

\section{English Equivalent}

Literally: It is- what-also-my-dressloose-that-this?

Meaning: What a nasty garment (you're wearing)!

Literally: You- can -afford-this?

Meaning: Certainly not the sort you can afford! INTERJECTION (= Yuck!)

Joking relatives usually tease and "abuse" each other jokingly, the one claiming to be the master of the other. As such they systematically tend to belittle or downgrade the qualities, possessions, appearance, etc. of each other, particularly when these are worth complimenting. It would therefore sound somewhat ridiculous for "a master" to become a sycophant for his "slave", hence the scarcity of "normal" complimenting among people from either side. 
(6) Context: A Mossi girl complimenting a dressed-up Gulmancema, young man, her joking relative.

Moore

Mossi girl: “Õ-õ ! Ad pa tog ne fye!

Mossi girl: Kẽng $n$ menem!

yãoã ya naam fuugu!

\section{English Equivalent}

Literally: INTERJECTION Behold-thisnot-suit-with-you!

Meaning: "Yuck! It doesn't suit you!"

Gulm. man: Fo pa ges frẽndã la? Ad Literally: You-not-look

at- your-own-then? Behold

-this - is-chieftaincy-garment!

Meaning: Haven't you had a look at yours? Mine is a royal garment!

Literally: Go-disappear!

Meaning: Go away!

As can be seen from (5) and (6), compliments between joking relatives look like castigation and are responded to as though they were such, but both complimenter and complimentee know inwardly that, in fact, they are compliments. In (5) the garment is described as ugly and unsuitable. In (6) the complimenter implicitly admits that the garment is beautiful but asserts that it doesn't suit the complimentee. In other words, the complimentee is deemed not worthy for such a nice garment. As it were, it is a negative evaluation which turns out to be actually interpreted positively by the complimentee who replies as though the 'complimenter' were (falsely) jealous of his garment and appearance.

Similar joking relationships exist within the Mossi ethnic group giving rise to similar complimenting patterns such as that between in-laws, for example. As rightly put by Pohl $(2004,2)$ "language users must share certain rules and conventions which enable [them] to understand one another [...] where the illocutionary force of utterances are not explicitly stated" (see also Yule $(1996,84)$ on coherence).

The rule in the above examples in Moore is: blatant castigation equates complimenting between joking relatives. This is not sarcasm, which is meant to really hurt, nor irony, which is often meant to laugh at the addressee, as in (7) and (8) respectively:

(7) A woman 'complimenting' her daughter who has just broken a valuable plate (a "shoddy job" as Agyekum (2010) puts it):

Moore

Woman: Ayay! F tvvmde!

F tvvm-toogo!

\section{English equivalent}

Literally: INTERJECTION Your-work!

Your-work-hard!

Meaning: Well done! Excellent job!”

Agyekum (2010) describes a similar case as an example of "a sarcastic performance compliment which implies the opposite of the compliment”. 
(8) Speaker (C) 'compliments' her addressee for inadvertently giving her purse to a scoundrel.

Moore

C: Fo pa kõ-a la f potmaanã la? F maan neere!

\section{English equivalent}

Literally:You-not-give-him-your-purse? You-did-beautiful!

Meaning: You have given him your purse, haven't you? Well done!

In (7) and (8) it is insincere complimenting which turns out to be real castigating, whereas in (5) and (6) it is insincere castigating which turns out to be real complimenting. This seems to go somewhat against Holmes' (1998:103) claim that "when the content of a compliment is perceived as too distant from reality, it will be heard as sarcastic or ironic-put down" even though sarcasm and irony can also be expressed in that way too in Moore as in (7) and (8).

Another form of implicit complimenting in Moore is found in Example (9):

(9) Context: A guest from the village of Niangouela visiting a relative in Ouagadougou

Moore

Guest: Iye! Yaa fo roog la wã bl?

Host: N yeyn.

Guest: ...

Host: ...

\section{English equivalent}

Literally: INTERJECTION Is-your-housethat-this-or (not)?

Meaning: Is this your house?

Literally: Yes.

Meaning: Yes, it is!

Guest: ...

Host: ...

Here, the guest expresses great admiration for the host's house (by means of the typical interjection "Iye!" expressing surprise) and goes on to ask "Is this your house?". But he remains silent (speechless?) after the host has confirmed his ownership of the house. The visit goes on and their conversation encompasses various topics (with the visitor sometimes looking around with admiration) but no explicit complimenting is heard. However, the host feels complimented. This could be described as silent complimenting and likened to "communicative silence" (Valkova, $(2013,49))$, 'eloquent silence', or 'rhetorical silence', or 'pragmatic silence' as used in the literature on the pragmatics of silence. (see Ephratt, 2008 for further insight into silence).

Pragmatic silence is also used in upward complimenting, that is, when the complimentee is of a higher social status or unknown to the (potential) complimenter. Then complimenting is expressed non-verbally. It is on subsequent occasions that potential complimenters will engage in talks mentioning the thing that was compliment-worthy: "Did you see his hat? It was just beautiful!". 


\section{Implications for politeness strategy}

The data examined here suggest that, in the Moore language, politeness strategy - of which complimenting is only one instance - does not function only on a bilateral face-to-face basis, but rather on a multilateral face-to-faces basis. Solidarity extends not only to all participants in the communicative event but also beyond to include absent third persons. This may account for why the Mossi have to be polite when talking about an absent third person, with or without other participants in the communicative event. The bare presence of a third person sometimes imposes polite conduct and talk not only between addresser and addressee, but also vis-à-vis absent third persons evoked in the conversation. As a matter of fact, the Moore language has polite 'address terms' for absent third persons, including " $M b a$ " + name, (literally "My father + name") "M'ma" + name, (literally "My mother" + name), and the third person plural pronoun "Bãmba" (often contracted as "Bãmb", "Ba" or " $B$ "), whose use is compulsory when talking about an absent third person who deserves respect in the eyes of the speaker, the addressee and/or the other participants or hearers. The designation "Address terms" may not be appropriate here as the absent third persons cannot actually be addressed, but the use of such linguistic items seems to testify that the absent are 'made present' in the communicative event when mentioned or evoked. Those titles are equivalent to the English "Mr", "Mrs", "Dr., and are used more often than not as address terms. In Moore, the use of the third person plural pronouns is compulsory when referring to an absent third person (singular) as a sign of respect and politeness towards them as in (10):

(10) Context: Speaker (S) is excusing an absent, honourable third person for not showing up at a meeting, and proposes to take his share to him.

Moore

$\mathrm{S}$ : "B pa na $n$ tõog $n$ wa rũndã ye. $M$ na rık $b$ pvurã $n$ taas-ba.”

\section{English equivalent}

Literally: They-not - can-

come-today. I-will- take-their-share -reach- them.

Meaning: "He can't come today. I will take his/her share to him/her".

That is why I would like to suggest that multilateral solidarity extended to absent third party should be given room in Brown and Levinson's (1987) theory of face and politeness. Considering the practice in Moore - and by no means exclusively - it seems reasonable to view politeness also as triggered and geared by a complex, virtual or real, face-to-faces encounter. This issue is further discussed in a forthcoming paper. Following Matsumoto $(1988,1989)$, a host of studies of politeness in Asian cultures (including Ide (1989) and Mao (1994), Haugh (2004), Cutrone (2011), Tao (2014) etc.) have challenged the universal character of Brown and Levinson's 
concept of face and politeness and have pointed out that 'social identity' which appears to be an important concept in Japanese and Chinese societies is not accounted for therein. Matsumoto (1988) (cited by Cutrone $(2011,52)$ ) explains that:

What is of paramount concern to a Japanese is not his/her own territory, but the position in relation to others in the group and his/her acceptance of others. Loss of face is associated with the perception by others that one has not comprehended and acknowledged the structure and hierarchy of the group

(ibid: 405)

Cutrone (2011) provides a good account of this debate. A few voices among African scholars also argue for paying due consideration to some African cultural realities in regard to face. Agyekum (2010), for example, describes the Akans' concept of face as 'communalistic' in nature and asserts that "While Akans share standards of "societal behaviour" that is recognizable to the social distribution of responsibility, Brown and Levinson's face theory focuses strongly on individual behaviour and responsibility" (Agyekum $(2010,14,21))$.

\section{Complimenting as one leg of the deontic evaluation tripod}

From the foregoing, it appears that Holmes' $(1986,485)$ definition of complimenting, which already allows room for third person complimenting, should be taken more strictly but only slightly modified as follows: " a speech act which explicitly or implicitly attributes credit to someone other than the addresser usually the person addressed, for some "good" (possession, characteristic, skill, etc.) which is positively valued by the addresser who assumes the recipient is pleased with the credit". Cross-cultural differences reside in the "which is positively valued by the addresser" since value judgements vary from culture to culture. I believe such a revision would allow all the potential complimenting types listed in Diagram 1 to fit in.

Furthermore, on observing complimenting behaviour and inquiring among native speakers of Moore, it appears that when impressed in one way or another by people's appearance, performance, possessions or personality, the Mossi display some degree of freedom to navigate between two opposite ends of a more general discursive behaviour which I would refer to as deontic evaluation: complimenting at the one end and castigating at the other. Deontic evaluation is individual and culture-specific value judgement of appearance, performance, possessions, or personality. It is impregnated with cultural values and norms and the realisation of either of its options (complimenting or castigating) is subject to culture-specific rules. For example, joking relationships offer the Mossi the possibility to castigate sincerely or insincerely with absolute impunity. Complimenting appears then to be one leg of this tripod phenomenon I have called deontic evaluation - 'indifference', 
the most likely interpretation of silence, constituting its third leg - and it may be better understood and described if addressed as such (see Diagram 3).

Beauty being in the eye of the beholder, compliments and castigations may vary in their objects by personal or cultural factors. The tendency to navigate between the opposite ends of this linguistic behaviour does not seem to be culture-specific to Moore as similar behaviour can be found across cultures around the world. That it is found in the UK is attested by the following example extracted by Jucker (2009, 1617) from the British National Corpus:

A: What did he say?

B: He said, you're a real roly-poly did you hear him?

A: Is that an insult or a compliment? (BNC KBL 5076)

However, cultures may differ as to which good or bad impressions can be exteriorized by means of compliments or castigation and which others must be kept inwardly according to the 'situational context'. Inwardly kept impressions may be rightly or wrongly assimilated to 'indifference' or implicit castigation. As Valkova $(2013,49)$ puts it "there are culture-bound expectations with compliments which may be so strong that the absence of a compliment may be perceived as a sign of disapproval". This may also apply to castigation whose absence in some circumstances may be assimilated to a sign of approval when disapproval is considered normal behaviour. Some cultures may be more prone to complimenting, others to castigating, and still others to apparent indifference.

Both complimenting and castigating seem to be realized much more often verbally than non-verbally (including silence), whereas indifference is 'silent' and 'non-verbally neutral'. Indifference - that is, silence - may be perceived either as

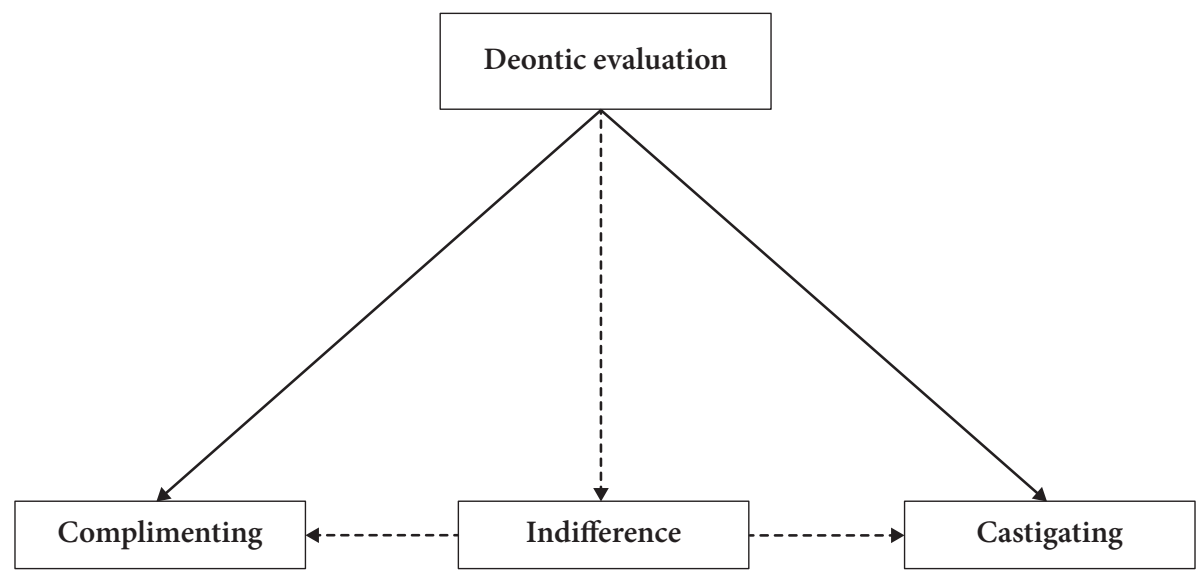

Diagram 3. The deontic evaluation tripod 
the absence of both complimenting and castigating, or worse, as castigating when complimenting is expected or as complimenting when castigating is expected. In either case it may hurt the feeling of the 'addressee' because it falls short of his/her expectations.

As corroborated by many studies in the field, the realisation patterns of complimenting are complex both intralingually (Holmes 1988) and, a fortiori, across languages and cultures. Most debates on compliments and their relevance according to context seem to boil down to navigating between the sub-types of deontic evaluation (complimenting, indifference, and castigating). Since complimenting varies by personal and cultural factors and takes on various forms across languages, it appears to be pragmatic error-prone for outsiders and, therefore, a very fertile field of investigation of pragmatic failures (Riley 1989; Thomas 1983). The revised definition of complimenting suggested in this paper could help towards a better understanding of what really counts as complimenting across languages and cultures.

\section{References}

Agyekum, Kofi. 2010. “The Ethnopragmatics of Akan Compliments.” Legon Journal of the Humanities 21: 13-38.

Brown, Penelope, and Stephen C. Levinson. 1987. Politeness: Some Universals in Language Use. Cambridge, England: Cambridge University Press.

Bruti, Silvia. 2006. "Cross-Cultural Pragmatics: The Translation of Implicit Compliments in Subtitles". The Journal of Specialised Translation 6: 185-197.

Chen, Rong. 1993. "Responding to Compliments: A Contrastive Study of Politeness Strategies between American English and Chinese Speakers." Journal of Pragmatics 20, 49-75. doi:10.1016/0378-2166(93)90106-Y

Clark, H. Herbert and Adrian Bangerter. 2004. “Changing Ideas about Reference.” In Experimental Pragmatics (Palgrave Studies in Pragmatics, Language and Cognition), ed. by Ira Noveck and Dan Sperber, 25-49. Houndmills: Palgrave Macmillan.

Cook, Guy. 1989. Discourse. Oxford University Press.

Cutrone, Pino. 2011. "Politeness and Face Theory: Implications for the Backchannel Style of Japanese L1/L2 Speakers.” Language Studies Working Papers 3: 51-57.

Daikuhara, Midori. 1986. "A Study of Compliments from a Cross-Cultural Perspective: Japanese vs. American English.” Working Papers in Educational Linguistics 2 (2): 103-134.

Duan, Yuanbing. 2011. "A Pragmatic Research Report on Compliment Speech Act, Theories and Practice." Language Studies. 1 (4): 356-360.

Ephratt, Michal 2008. “The Functions of Silence." Journal of Pragmatics 40: 1909-1938. doi:10.1016/j.pragma.2008.03.009

Franch, P. Bou. 1998. “On Pragmatic Transfer." Studies in the English Language and Linguistics, 0: 5-20.

Furko, B. Péter, and Eva Dudas. 2012. "Gender Differences in Complimenting Strategies with Special Reference to the Compliment Response Patterns of Hungarian Undergraduate Students." Argumentum 8: 136-157. 
Grossi, Vittoria. 2009. “Teaching Pragmatic Competence: Compliments and Compliment Responses in the ESL Classroom.” Prospect Journal 24 (2): 53-62. http://www.ameprc.mq.edu. au/docs/prospect_journal/volume_24_no_2/Vittoria_Grossi.pdf.

Haugh, Michael. 2004. "Revisiting the Conceptualisation of Politeness in English and Japanese." Multilingua 23: 85-109. doi:10.1515/mult.2004.009

Herbert, K. Robert 1986. “Say “Thank you”-or Something.” American Speech 61 (1): 76-88. doi: $10.2307 / 454710$

Herbert, K. Robert 1990. “Sex-Based Differences in Compliment Behavior." Language in Society 19: 201-224. doi:10.1017/So047404500014378

Herbert, K. Robert. 1989. "The Ethnography of English Compliments and Compliment Responses: A Contrastive Sketch.” In Contrastive Pragmatics, ed. by Oleksy, Wieslaw, 3-35. Amsterdam: John Benjamins.

Hobbs, Pamela. 2003. “The Medium is the Message: Politeness Strategies in Men's and Women's Voice Mail Messages.” Journal of Pragmatics 35 (2): 243-262. doi:10.1016/So378-2166(02)o0100-5

Holmes, Janet. 1986. "Compliments and Responses in New Zealand English." Anthropological Linguistics 28 (4): 485-508.

Holmes, Janet. 1988. "Paying Compliments: A Sex-Preferential Positive Politeness Strategy." Journal of Pragmatics 12 (3): 445-465. doi:10.1016/0378-2166(88)90005-7

Holmes, Janet. 1995. Women, Men, and Politeness. London: Longman.

Holmes, Janet. 1998. “The Linguistic Construction of Gender Identity." Wellington Papers in Linguistics 10: 1-10.

Holmes, Janet, and D. Brown. 1987. “Teachers and Students Learning about Compliments." TESOL Quarterly 21 (3): 523-546. doi:10.2307/3586501

Hymes, Dell. 1974. Foundations of Sociolinguistics: An Ethnographic Approach. Philadelphia: University of Pennsylvania Press.

Ide, Sachiko. 1989. "Formal Forms and Discernment: Two Neglected Aspects of Universals of Linguistic Politeness." Multilingua 8: 223-248. doi:10.1515/mult.1989.8.2-3.223

Jucker, Andreas. H. 2009. "Speech Act Research between Armchair, Field and Laboratory: The Case of Compliments”. Journal of Pragmatics 41: 1611-1635. doi:10.1016/j.pragma.2009.02.004

Jucker, Andreas H., Gerold Schneider, Irma Taavitsainen, and Barb Breustedt. 2008. "Fishing for Compliments: Precision and Recall in Corpus-Linguistic Compliment Research." In Speech Acts in the History of English, ed. by Andreas. H. Jucker, and Irma Taavitsainen, 273-294. Amsterdam/Philadelphia: John Benjamins. doi:10.1075/pbns.176.15juc

Lewandowska-Tomaszcyk, Barbara. 1989. "Praising and Complimenting." In Contrastive Pragmatics, ed. by W. Olesky, 73-100. Amsterdam: John Benjamin Publishing Co.

Manes, Joan, and Nessa Wolfson. 1981 “The Compliment Formula.” In Conversational Routine. Explorations in Standardized Communication Situations and Prepatterned Speech, ed. by Florian Coulmas, 115-132. The Hague: Mouton.

Mao, R. LuMing. 1994. “Beyond Politeness Theory: “Face” Revisited and Renewed." Journal of Pragmatics 21: 451-486. doi:10.1016/0378-2166(94)90025-6

Matsumoto, Yoshiko. 1988. "Re-examination of the Universality of Face: Politeness Phenomena in Japanese.” Journal of Pragmatics 12: 403-426. doi:10.1016/0378-2166(88)90003-3

Matsumoto, Yoshiko. 1989. "Politeness and Conversational Universals: Observations from Japanese." Multilingua 8: 207-221. doi:10.1515/mult.1989.8.2-3.207

Mustapha, A. Samuel. 2012a. "A Functional Approach to Identifying the Compliment Data." Rice Working Paper in Linguistics. 3: 1-15. 
Mustapha, A. Samuel. 2012b. “Approaches to Identifying the Compliment Data." International Journal of English Linguistics 2 (1): 220-230. doi:10.5539/ijel.v2n1p220

Othman, Normala. 2011. "Pragmatic and Cultural Considerations of Compliment Responses among Malaysian-Malay Speakers." Asiatic 5 (1): 86-103.

Pohl, Gabriela. 2004. "Cross-Cultural Pragmatic Failure and Implications for Language Teaching." Second Language Learning and Teaching (SSLT)", http://www.apacall.org/member/sonjb/sllt/ Vol. 4, Retrieved date 12/08/2015.

Pomerantz, Anita. 1978. "Compliment Responses: Notes on the Cooperation of Multiple Constraints”. In Studies in the Organization of Conversational Interaction, ed. by Jim Schenkein, 79-112. New York, NY: Academic Press.

Riley, Philip. 1989. "Well don't blame me! - On the Interpretation of Pragmatic Errors." In Contrastive Pragmatics, ed. by Wieslaw Oleksy, 231-249. Amsterdam: John Benjamins Publishing Company.

Searle, John R. 1969. Speech Acts: An Essay in the Philosophy of Language. Cambridge: Cambridge University Press.

Shokouhi, Saeedeh, and Amir Rezaei. 2015. "The Importance of Teaching Pragmatics in the Classroom (Focus on Complimenting)." Journal for the Study of English Linguistics 3 (1): 101-107. doi:10.5296/jsel.v3i1.7890

Tajeddin, Zia and Elham Yazdanmehr. 2012. "Investigating the Structural Pattern and Pragmatic Functions of Compliments Made by Iranian EFL Learners." Journal of English Language Teaching and Learning 10: 27-51.

Tao, Lin. 2014. "Evaluating the Concept of 'Face' (Mentsu) in Japanese Verbal Communication." Intercultural Communication Studies XXIII (1): 112-124.

Thomas, Jenny. 1983. “Cross-Cultural Pragmatic Failure.” Applied Linguistics 4 (2): 91-112. doi:10.1093/applin/4.2.91

Válková, Silvie. 2013. "Speech Acts or Speech Act Sets: Apologies and Compliments." Linguistica Pragensia 2/2013: 44-57.

Wierzbicka, Anna. 1991. Cross-Cultural Pragmatics: The Semantics of Human Interaction. Berlin: Walter de Gruyter \& Co.

Wolfson, Nessa. 1981. “Compliments in Cross-Cultural Perspective." TESOL Quarterly 15 (2): 117-124. doi: $10.2307 / 3586403$

Wolfson, Nessa. 1983. "An Empirically Based Analysis of Complimenting in American English." In Sociolinguistics and Language Acquisition, ed. by Nessa Wolfson, and Elliot Judd, 82-95. Rowley, MA: Newbury House.

Yuan, Yi. 2002. "Compliments and Compliment Responses in Kunming Chinese." Journal of Pragmatics 12/2: 183-226. doi:10.1075/prag.12.2.04yua

Yule, George. 1996. "Pragmatics." In Oxford Introductions to Language Study, ed. by Henry G. Widdowson. Oxford: Oxford University Press.

\section{Author's address}

Mahamadou Sawadogo

Department of Anglophone Studies

Ouaga-I Prof. Joseph Ki-Zerbo University

Burkina Faso

madi.sawa@yahoo.fr

mahamadou.sawadogo@univ-ouaga.bf 